\title{
Neuromyelitis optica: it is time to move one step further
}

\author{
Neuromielite óptica: é hora de dar um passo adiante
}

Tarso Adoni $i^{1,2}$

${ }^{1}$ Hospital Sírio-Libanês, São Paulo SP, Brasil;

2Universidade de São Paulo, Faculdade de Medicina, Hospital das Clínicas, Departamento de Neurologia, São Paulo SP, Brasil.

\section{Correspondence:}

Tarso Adoni; Rua Dona Adma Jafet, 74 / conj. 121;01308-050 São Paulo SP, Brasil;

E-mail:tarso@dfvneuro.com.br

Conflict of interest:

There is no conflict of interest to declare.

Received 17 January 2017

Accepted 24 January 2017

\section{(cc) BY}

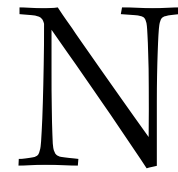

euromyelitis optica (NMO) is an autoimmune inflammatory channelopathy of the central nervous system mediated by serum antibodies against aquaporin-4 (AQP4-IgG), which affects mainly the optic nerves and the spinal cord ${ }^{1}$. An International Panel of experts convened in 2015 and replaced the term NMO with NMO spectrum disorders (NMOSD) with the aim of including the typical limited forms of the syndrome, namely: myelitis, optic neuritis, area postrema syndrome, acute brainstem syndrome, acute diencephalic syndrome or narcolepsy, and symptomatic cerebral brain lesions with brain MRI findings of NMOSD. The exclusion of alternative diagnoses remains mandatory and, keeping this in mind, according to the Panel it is now possible to render the diagnosis of NMOSD even for those patients with AQP4-IgG status unknown².

The concept of a "spectrum" of NMO is very welcome in the hands of experts, taking into account the recurrent pattern of the disease and its severity, thus allowing early diagnosis and treatment. On the other hand, it can pose problems and diagnostic errors for the non-specialist. As a result, the best way to minimize errors and improve diagnostic accuracy in general is to know, as much as possible, the range of clinical manifestations of the disease as well as its behavior in the long term.

In this issue of Arquivos de Neuropsiquiatria, Del Negro et al. ${ }^{3}$ add clinical information about 34 Brazilian patients diagnosed with NMOSD and 40 patients with longitudinally extensive transverse myelitis (LETM). There are few differences from the previously published Brazilian series, which is not a weakness of the study but confirms our knowledge and reinforces the role of reliable science in replicating results. Worthy of note was the finding of autoimmunity markers more often in monophasic than in relapsing forms of $\mathrm{NMO}^{4}$. According to the authors, this finding may be a result of the small sample size. As for MRI, it would be interesting that the authors had verified the existence of bright spotty lesions (BSL, similar or higher in signal intensity than cerebrospinal fluid on the axial T2W images) given that these have been shown to be highly sensitive and specific in the diagnosis of LETM that occur in the context of NMOSD ${ }^{5}$. Pekcevik et al. ${ }^{6}$ showed that BSL was found to be a specific finding (sensitivity: 64.6\%; specificity: $89.1 \%$ ) for differentiating NMO from MS and NMO from all the other causes of LETM.

Del Negro et al. ${ }^{3}$ discuss the characteristics of other Brazilian series (in table 4) and a quick glance shows 155 cases of NMOSD patients studied since 2002. The problem of the small size of the series could be solved with multicenter studies and the creation of a national database $^{7}$. A multicenter German study (NEMOS) was able to gather 175 patients with NMOSD ${ }^{8}$. Considering the continental dimensions of Brazil, we would be able to gather an even greater number of cases.

We must realize that now is the time to take a step further, moving beyond papers that repeat and confirm to exhaustion the clinical and epidemiological characteristics of NMOSD. It is time to join efforts to facilitate access to the AQP4-IgG test throughout the national territory with the best available technique 9 . It is time to expand and establish the conditions to carry out the anti-MOG research in our country ${ }^{10}$. It is time to work together for a better understanding of the pathophysiology of NMOSD, in order to answer why there are seronegative forms or why there are mechanisms of injury that do not depend on the activation of the complement ${ }^{11}$. This is how we will take the lead in NMOSD research and we will be able to effectively contribute to a better quality of life for our patients. 
1. Pittock SJ, Lucchinetti CF. Neuromyelitis optica and the evolving spectrum of autoimmune aquaporin-4 channelopathies: a decade later. Ann NY Acad Sci. 2016;1366(1):20-39. http://doi.org/10.1111/nyas.12794

2. Wingerchuk DM, Banwell B, Bennett JL, Cabre P, Carroll W, Chitnis T et al. International consensus diagnostic criteria for neuromyelitis optica spectrum disorders. Neurology. 2015;85(2):177-89. http://doi.org/10.1212/WNL.0000000000001729

3. Del Negro MC, Marinho PBC, Papais-Alvarenga RM.

Neuromyelitis optica: phenotypic characteristics in a Brazilian case series. Arq Neuropsiquiatr. 2017;75(2):81-6. http://doi.org/10.1590/0004-282X20160193

4. Pittock SJ, Lennon VA, Wingerchuk DM, Homburger HA, Lucchinetti CF, Weinshenker BG. The prevalence of non-organ-specific auto antibodies and NMO IgG in neuromyelitis optica (NMO) and related disorders. Neurology. 2006;66:A307.

5. Yonezu T, Ito S, Mori M, Ogawa Y, Makino T, Uzawa A et al. "Bright spotty lesions" on spinal magnetic resonance imaging differentiate neuromyelitis optica from multiple sclerosis. Mult Scler. 2014;20(3):331-7. http://doi.org/10.1177/1352458513495581

6. Pekcevik Y, Mitchell CH, Mealy MA, Orman G, Lee IH, Newsome $\mathrm{SD}$. et al. Differentiating neuromyelitis optica from other causes of longitudinally extensive transverse myelitis on spinal magnetic resonance imaging. Mult Scler. 2016;22(3):302-11. http://dx.doi.org/10.1177/1352458515591069

7. Lana-Peixoto MA, Talim LE, Faria-Campos AC, Campos SV, Rocha CF, Hanke LA et al. NMO-DBr: the Brazilian Neuromyelitis Optica Database System. Arq Neuropsiquiatr. 2011;69(4):687-92. http://dx.doi.org/10.1590/S0004-282X2011000500021

8. Jarius S, Ruprecht K, Wildemann B, Kuempfel T, Ringelstein $\mathrm{M}$, Geis $\mathrm{C}$ et al. Contrasting disease patterns in seropositive and seronegative neuromyelitis optica: a multicentre study of 175 patients. J Neuroinflammation. 2012;9(1):14. http://doi.org/10.1186/1742-2094-9-14

9. Waters PJ, Pittock SJ, Bennett JL, Jarius S, Weinshenker BG, Wingerchuk DM. Evaluation of aquaporin-4 antibody assays. Clin Exp Neuroimmunol. 2014;5(3):290-303. http://doi.org/10.1111/cen3.12107

10. Sato DK, Callegaro D, Lana-Peixoto MA, Waters PJ, Haidar Jorge FM, Takahashi T et al. Distinction between MOG antibody-positive and AQP4 antibody-positive NMO spectrum disorders. Neurology. 2014;82(6):474-81. http://doi.org/10.1212/WNL.0000000000000101

11. Takeshita Y, Obermeier B, Cotleur AC, Spampinato SF, Shimizu F, Yamamoto E et al. Effects of neuromyelitis optica-IgG at the blood-brain barrier in vitro. Neurol Neuroimmunol Neuroinflamm. 2016;4(1):e311. http://doi.org/10.1212/NXI.0000000000000311 